\title{
DANTE ALIGHIERI: O INFERNO E FLORENÇA
}

\section{Acilon H.B. Cavalcante}

Instituto de Estudos Superiores da Amazônia

\section{Resumo}

Dante Alighieri: O Inferno e Florença, é um perfil traçado sobre o poeta florentino que viveu entre os séculos XIII e XIV na cidade italiana de Florença. Apesar de conhecido pelo Inferno, livro introdutório da sua Divina Comédia, ele também foi político, embaixador, intelectual, reformista e poeta que participou ativamente dos planos e destinos de sua cidade. Este perfil irá buscar suas raízes intelectuais, comogênicas e religiosas, além de sua relação com Florença, para delinear o legado que este eurudito trouxe à sociedade ocidental com parâmetros que duram até os dias de hoje.

Palavras-chaves: Dante, Florença, Divina Comédia.

\section{Abstract}

Dante Alighieri: The Inferno and Florence, is profiled on the Florentine poet who lived between the thirteenth and fourteenth centuries in the Italian city of Florence. Although known for Inferno, introductory book of his Divine Comedy, he was a politician, ambassador, intellectual, reformer and poet who actively participated in the plans and destinations of his city. This profile will get their intellectual roots, comogênicas and religious, and his relationship with Florence, to outline the legacy that brought Western society with parameters that last until today.

Keywords: Dante, Florence, Divine Comedy.

\section{Introdução}

"A meio do caminhar de nossa vida, fui me encontrar em uma selva escura,"1 uma selva que Dante Alighieri, poeta florentino do século XIII e considerado um dos maiores pensadores do mundo europeu medieval, deixou como legado à sociedade ocidental. No mundo contemporâneo, a aceitação de um universo que permita reinos dos mortos como os descritos na Divina Comédia: o Inferno, o Purgatório e o Paraíso, é possível somente entre religiosos e instituições ligadas à Igreja. Na chamada "Idade das Trevas" no entanto, além dos reinos dos mortos, a cultura da época permitia a experiência cotidiana com seres imateriais, em que os santos e anjos, representantes

\footnotetext{
${ }^{1}$ DC, Canto I, 1.
} 
do bem e da Igreja, e os demônios, arquétipos do "mal", são quase sempre deslocados para a floresta, o lugar do estranho, da negação, citada por Dante como a "Selva Escura", longe da luz do burgo.

Ao tomar as devidas diferenças entre o século XIII e o atual, é impressionante como uma obra escrita naquele período ainda seja lida, publicada, estudada e mais, faça parte do imaginário ocidental, adaptada de diversas formas para a cultura popular, presente no cinema, nos quadrinhos, nos games, nas artes e na literatura. Também é importante salientar que exista no meio acadêmico um número grande de estudos relacionados à obra do poeta, principalmente no Reino Unido e nos Estados Unidos. No século XIX, na Inglaterra, a poesia e a vida de Dante Alighieri tornou-se "febre" nas academias, e alguns teóricos nacionais como Hilário Franco Jr (2000), da Universidade de São Paulo e Eduardo Sterzi (2010), apontam esse fato como resultado do contexto que o Reino Unido viveu desde o século XVIII e continuando pelo século XIX, de Revolução Industrial e crescimento desordenado das cidades, o que fez o trabalho de artistas como William Blake, Miltom ${ }^{2}$ e Dante Gabriel Rossetti revalorizassem a poesia e o imaginário criado pelos versos de Dante, o mesmo também ocorreu na França, através de exemplos como o do famoso gravurista Gustave Doré, do pintor Eugéne Delacroix e do escultor Auguste Rodin, todos com leituras imagéticas do acervo dantesco.

Para traçar a trajetória de Dante nesta demanda por euruditos e suas relações com a cidade, é necessário antes explorar o gênio criativo de seu autor, fato que será feito através do seu perfil religioso, intelectual e político. Para situar o autor em seu tempo, foi feito um estudo da configuração social, política e religiosa de sua Florença, quase uma topografia, que refletiu-se na sua obra literária quando interpôs referências e personalidades de sua cidade no Inferno. Assim, além do perfil do poeta, do traçado de sua cidade, também será explorado o Cosmos Medieval, de forma a apontar a ideia que Dante tinha da situação do homem ante ao Universo, a Natureza e sua própria Florença.

\subsection{O POETA DO INFERNO}

Dante Alighieri ficou conhecido por ser o poeta medieval que "estruturou" e deu aparência ao Inferno, descrevendo como nenhum outro fizera até então os horrores dos castigos da eternidade. O que ocorre, no entanto, é que ele não foi somente o "poeta do Inferno", o pesquisador em História Medieval, Hilário Franco Jr. (2000) afirma que a poesia foi nada mais que o canal por onde Dante foi capaz de

\footnotetext{
${ }^{2}$ Escritor do Século XIX, autor de o Paraíso Perdido.
} 
expressar sua "genialidade", e por onde expressava seus sentimentos, suas opiniões políticas, reformadoras e religiosas.

Além de seu intelecto e perfil de poeta, há outros pontos importantes de sua biografia que devem ser revelados: ele era uma político atuante do Partido dos Guelfos, uma das várias facções políticas de sua terra natal: Florença. Atuou na diplomacia, tanto em sua cidade quanto em outras cidades-estado da Itália no período de seu exílio. O trecho descrito pelo especialista em Dante, Eduardo Sterzi (2010), demostra muito bem o tamanho da fama e da importância que o poeta alcançara em vida ao citar o medo dos governantes venezianos de que ele, pelo poder de sua retórica, convencesse o Almirante a trocar de lado:

O ano é 1321. O embaixador de Ravena ${ }^{3}$ - depois de mais de um mês de missão diplomática em Veneza, da qual resultaria a paz entre as duas cidades - Está retornando para a corte de Guido Novello da Polenta. Não se desloca por mar, mas por terra, atravessando os pantanosos arredores do Comacchio. Segundo especula o cronista Fillippo Villani, a viagem marítima teria sido proibida pelos venezianos, por temerem que o embaixador, com seu inigualável poder retórico, convencesse o almirante a colocar a frota sob o domínio de Ravena. Em alguma hora indeterminada da noite de 13 para 14 de setembro, o embaixador morre, provavelmente acometido de malária. Tem pouco mais de 56 anos; não atingiria, portanto, os setenta que, conforme registrara, na trilha de Aristóteles e das Escrituras, reputava a idade perfeita. (STERZI, 2010, p.14).

\subsection{BIOGRAFIA}

Um dos maiores problemas em relação à biografia de Dante é que pouco se sabe realmente sobre sua vida. Seu maior biógrafo, considerado pelos pesquisadores da atualidade, foi também seu maior entusiasta, capaz de criar citações a respeito de seu nascimento a partir de uma narrativa mitológica. Todos os elementos presentes na citação de Giovanni Bocaccio (citado por STERZI, 2010) apontam símbolos como o "altíssimo loureiro", "a fonte de águas claras", "alimentar-se dos loureiros" e por fim o próprio "pavão", conforme descreve no texto a seguir:

Segundo conta, a mãe de Dante, quando grávida, teve um sonho profético em que se via dando a luz ao pé de um "altíssimo loureiro", ao lado de uma fonte de águas claras. O filho, no sonho, logo se passava a alimentar-se dos frutos dos loureiros e a beber da fonte, torna-se, então, um grande pastor", que comprazia à sombra da árvore; como desejava os frutos que caíam ao chão, também ele se deixava cair; mas, para surpresa da mãe sonhadora, do solo não se erguia o filho, mas um belíssimo "pavão". (BOCACCIO citado por STERZI, 2010, p.27).

\footnotetext{
${ }^{3}$ O Embaixador de Ravena a que se refere esta citação é Dante Alighieri.
} 
Em relação à citação acima, o loureiro, também conhecido como árvore de $\mathrm{Phebo}^{4}$, tem seus frutos associados ao conhecimento da Teologia e da Filosofia. De acordo com o "Dicionário de Símbolos", de Udo Becker (1999, p. 172), o loureiro teve seu significado alterado ao longo das eras, passando, no início, como símbolo da imortalidade, pelo fato de suas folhas nunca perderem o verde e, ao final, como símbolo da vitória e do triunfo, comumente associado à atletas e, na época de Bocaccio e Dante, aos poetas.

O pavão fazia referência a sua obra, também associado ao sol no Cristianismo, que também trata de Phebo na mitologia grega, coloca ainda mais adiante que o pavão possuía os pés sujos, referência ao uso da língua comum, em detrimento do latim para expressar-se, mais tarde quando for analisado o seu perfil de poeta, será evidenciado o quanto representou em termos de evolução literária para a época.

As citações de Bocaccio sobre Dante tendem a colocá-lo como uma figura épica, abusando da liberdade poética para posicionar o poeta florentino como um ser quase mitológico. Por isso, muito do que se sabe sobre Dante não passa de especulação como, por exemplo, a data de seu nascimento. O único elemento factual a respeito desta data está relacionado ao seu batizado: 26 de março de $1266^{5}$, segundo conta a tradição, os nascidos no ano anterior, no caso em 1265, foram batizados no sábado de Aleluia, e a história não transmite nada mais que isso. Outro elemento que dá pistas da data está fincado no canto XXII, do Paraíso: se do fogo a escapar não foi mais lento, / que o teu, meu dedo, quando apareceu / dos Gêmeos o astro, e nele tive assento. (Divina Comédia, Canto XXII, 109, trad. em MAURO, 1998).

Tal trecho posiciona o seu nascimento sob o signo de Gêmeos. Os dois maiores biógrafos do poeta nos dias atuais são, segundo Sterzi (2010), Giorgio Petrocchi e Robert Hollander. De acordo com o primeiro, a data mais provável para o nascimento de Dante foi entre 14 de maio e 13 de junho, tendendo mais para o fim de maio $^{6}$ e ainda afirma que qualquer data mais precisa seria uma irresponsabilidade.

O nome de batismo de Dante era Durante, sendo o primeiro uma contração e, provavelmente, seu nome seria uma homenagem ao avô materno. Quanto à ascendência do poeta, pode-se afirmar que ele descendia do Cavaleiro Cruzado

\footnotetext{
${ }^{4}$ De acordo com Becker (1999), o louro é uma planta que permanece sempre verde, por isso, é símbolo da imortalidade. Por proteger contra raios, foi associada ao deus Apolo e, na Grécia, chamado de Phebo. ${ }^{5}$ STERZI (2010, p. 25).

${ }^{6}$ STERZI $(2010$, p. 26).
} 
Cacciacuda, sendo tataraneto dele, fato relatado em trecho do Paraíso entre os cantos XV e XVIII. "Ó sangue do meu, ó sobre a infusão / a graça de Deus, assim como você estava a quem / o dobro, a qualquer momento recusar-se a porta do céu?' (Divina Comédia, Paraíso, Canto XV, 28, trad. em MAURO, 1998). Era filho de Alighiero II e Bella, que supõe ser da família Abati $^{8}$, filha do Magistrado Durante Abati, de onde especula-se veio o seu nome. Seu avô paterno era Bellincioni Alighieri, colocado por Sterzi como a maior influência literária do neto e também sua maior fonte de informação sobre a História de Florença.

A educação de Dante, de acordo com Petrocchi citado por Sterzi (2010), pode ser dividida em três etapas com datas aproximadas, sendo a primeira relativa aos ensinamentos de Retórica e Gramática, entre 1275 e 1286 . No final desta etapa, em 1286, que conheceu Brunetto Latini, ilustre professor que representou para toda a jovem intelectualidade florentina "o ponto de cruzamento entre a literatura clássica latina, a retórica e a filosofia medieval e a poesia vernacular francesa" (STERZI, 2010, p. 38). No tópico seguinte, as influências literárias do poeta serão mais aprofundadas.

A segunda fase na educação de Dante foi entre 1287 e 1290, quando estudou Filosofia e Literatura. Nesta fase, consta, a amizade do poeta Guido Cavalcanti $^{9}$ foi de grande importância, além de uma estada na cidade de Bolonha, onde pôde aprofundar seus estudos.

A fase seguinte de sua educação deu-se, aproximadamente, entre 1291 e 1295, quando ingressou nas escolas religiosas para realizar estudos na área da Filosofia Teológica. Após essa etapa, ingressou na corporação dos médicos e apotecários, exigência para quem quisesse ingressar na vida pública.

\subsubsection{O Político}

Para entender a formação e atuação política de Dante Alighieri, é necessário entender o contexto político pela qual passava Florença e o que era a cidade para a Europa nesta época. Florença, em 1265, ano do nascimento do artista, era um dos maiores centros urbanos e econômicos do continente, com cerca de 100 mil habitantes, aproximando-se dos 200 mil que habitavam Paris, maior cidade do mundo medieval, conforme afirma o historiador urbano Leonardo Benévolo (1997): "As cidades mais populosas - Milão e Paris - alcançaram talvez 200 mil habitantes, Veneza

\footnotetext{
${ }^{7}$ Fala de Cacciacuda a Dante.

${ }^{8}$ STERZI (2010, p. 34).

${ }^{9}$ De acordo com o estudioso de Dante, Hilário Franco Jr. (2000), Guido Cavalcante foi o primeiro nome do estilo poético que Dante desenvolvera em sua obra, oriundo da Provença francesa e na Vita Nuova, ele chega a mencioná-lo como "o primeiro dos meus amigos" (FRANCO JR., 2000, p. 27).
} 
150 mil, Florença, 100 mil; Gand e Bruges, 80 mil; Siena 50 mil." (BENÉVOLO, 1997, p. 283).

Florença, além de ser uma das maiores cidades de seu tempo, era também um grande centro comercial, como atesta Franco Jr. (2000), no texto abaixo:

Em meados do século XIII Florença lançava uma nova moeda, o florim de ouro, que logo se tornou de circulação internacional. Na época do nascimento de Dante, Florença era sem dúvida o grande centro financeiro ocidental, com comerciantes e banqueiros espalhados por toda a Europa e servindo clientes como o Papado e a monarquia da Inglaterra (FRANCO Jr., 2000, p.23).

Benévolo (1997) aponta esse crescimento econômico como reflexo do que ocorrera na Europa como um todo, fruto da estabilização dos últimos povos invasores, os vikings, os árabes e os húngaros; as inovações nas técnicas de agricultura como a rotação trienal das culturas e os novos sistemas de encangar cavalo e boi e a difusão dos moinhos d'água. Por último, a influência que as cidades marítimas da Itália exerceram no comércio internacional, sendo as principais Veneza, Gênova, Pisa e Amalfi.

Esse conjunto de elementos provocou uma explosão demográfica no continente, pulando de 22 milhões de habitantes em 950, para 55 milhões em 1350. Logicamente, os sistemas de possessões também modificam-se, assim como os sistemas políticos e as estruturas institucionais, formando as "cidades-estado", dentre as quais, Florença e, de acordo com Sterzi, o primeiro Estado Moderno do planeta ${ }^{10}$.

A organização política das cidades-estado era relativamente simples, conforme salienta Benévolo: "A nova organização surge, num primeiro tempo, como associação privada, depois se embate com os bispos e os príncipes feudais, e se torna poder público." (BENÉVOLO, 1997, p. 260). Este é o ponto de partida para a Comuna que, na prática, é um Estado, com lei própria. Os principais órgãos administrativos eram o Conselho Maior, formado pelas famílias mais importantes, o Conselho Menor, que era o Poder Executivo e os magistrados que, na Itália, chamava-se Consoli. Dante foi um dos seis membros do Conselho que dirigia a cidade. A sociedade também era organizada em corporações de ofícios, chamadas de Guilds, na Inglaterra, e Arti, na Itália.

É no século do nascimento de Dante que Florença tem sua explosão demográfica e econômica, evoluindo de uma Comuna criada, em 1115, com cerca de 20 mil habitantes para 100 mil no século XIII. A principal atividade econômica da

\footnotetext{
${ }^{10}$ STERZI $(2010$, p. 32)
} 
cidade era a tecelagem, tornando-se o berço industrial da Europa. No início desse século, surgem as corporações na indústria e no comércio, reflexo do desenvolvimento econômico da cidade, mas como afirma Benévolo (1997), sempre enfrentando crises:

A Comuna entra periodicamente em crise devido às lutas entre os guelfos e os gibelinos (vitória dos guelfos e governo do "primeiro povo" em 1250; regresso dos gibelinos depois de Montaperti em 1260; novo governo guelfo dominado pelos mercadores em 1267). (BENÉVOLO, 1997 , p. 360).

A diferença prática entre esses dois partidos é que os Guelfos apoiavam o Papa, enquanto os Gibelinos apoiavam o Sacro-Império Romano que, na verdade, tinha suas raízes na Alemanha e nos tempos em questão estava a cargo de Frederico I. O exílio de Dante foi durante um período em que o partido Guelfo estava no poder, em 1300, e ele mesmo partira como embaixador da cidade em missão diplomática a Roma. Os partidos eram formados por famílias e ele mesmo nascera entre os Guelfos. Sterzi (2010) lembra que, no ano de seu batismo, 1266; vários parentes seus encontravam-se no exílio.

No partido de Dante, de acordo com Franco Jr. (2000), existia a divisão entre Negros e Brancos, sendo os primeiros provenientes da antiga e decadente nobreza e os seguinte burgueses que haviam ascendido ao poder. Apesar de Dante ter laços de parentescos com os Negros, não se sabe o motivo de ele ter filiado-se aos Brancos ${ }^{11}$. Em 1301, fora a Roma como embaixador e desta viagem não mais retornara. Como o Papa Bonifácio VIII não via com bons olhos os Brancos, de origem burguesa, ele encomendara junto aos franceses uma força militar que invadira Florença dando poderes aos Negros. A partir de então, os membros Brancos do alto escalão foram condenados a pagar uma multa e viver dois anos em exílio. Dante não concordou com a condenação e não se apresentou para cumprir pena, fato que o levou à condenação capital caso retornasse a sua cidade. Ele nunca mais retornaria a ela.

\subsubsection{O Poeta}

Além de seus feitos na política e sua erudição, o que fez de Dante "imortal" foi sua poesia, e apesar de toda fama e prestígio que possui a Comédia, o documento considerado a certidão de nascimento da consciência literária italiana é Vita Nuova ${ }^{12}$, trabalho de forte influência das transformações culturais que ocorriam desde o sul da

\footnotetext{
${ }^{11}$ FRANCO JR. (2000, p. 31).

${ }^{12}$ De Robertis citado por STERZI (2010, p. 75).
} 
França até a Itália, no chamado Renascimento do século XII, como cita Sterzi (2010) em seu texto:

Em que consistiu a Renascença Medieval? Foi no século XII que a Europa viu surgirem das mais importantes práticas e instituições que seriam as suas ao longo dos séculos seguintes, com a formação de uma nova atmosfera econômica e política, mas também cultural e comportamental. (STERZI, 2010, p. 52)

Uma influência que certamente acertou o poeta, foi a da cultura trovadoresca, oriunda da região francesa conhecida como Ocitânia ${ }^{13}$. Esta influência explica a relação entre Dante e Beatriz, pois de acordo com Sterzi o amor no estilo trovadoresco italiano era sobretudo "amor espiritual, sublimado" (STERZI, 2010, p. 69).

Portanto, para falar do Dante poeta, é sem sombra de dúvida falar de Beatriz. Até os tempos de Dante, as musas estavam banidas da Europa, os versos que são dedicados a ela tanto em "Vita Nuova" quanto na "Comédia", celebram um novo gênero literário baseado em uma cultura clássica, já extinta.

Fica claro então, que apesar de o Inferno ser sua obra mais comentada, é nos assuntos amorosos que Dante se desataca enquanto poeta, desde a gênese de seu processo, quando aos 18 anos encontra com Beatriz e esta o cumprimenta, fazendo com que Dante ouvisse sua voz pela primeira vez: "Como que inebriado, Dante afasta-se das pessoas e recolhe-se ao seu quarto solitário, onde se põe a pensar sobre a amada." (STERZI, 2010, p. 30). Este acontecimento teve como fruto o primeiro soneto, presente na Vita Nuova: Ciascun'alma presa e gentil core (A cada alma enamorada e gentil coração).

A ciascun'alma presa e gentil core nel cui cospetto ven lo dir presente, in ciò che mi rescrivan suo parvente salute in lor segnor, cioè Amore.

Già eran quasi che atterzate l'ore del tempo che onne stella n'è lucente, quando m'apparve Amor subitamente, cui essenza membrar mi dà orrore.

Allegro mi sembrava Amor tenendo meo core in mano, e ne le braccia avea madonna involta in un drappo dormendo.

Poi la svegliava, e d'esto core ardendo lei paventosa umilmente pascea:

${ }^{13}$ Região do Sul da França, também conhecida como Provença. 
appresso gir lo ne vedea piangendo. ${ }^{14}$

Na própria obra do Inferno, é também possível enxergar o papel que o amor ocuparia em sua poesia. No II Círculo Infernal, encontra com Francesca de Rimini e seu amante Paolo e é onde surge, para nós, um dos versos mais belos deste livro:

Amor, que alma gentil pronto apreende, / este prendeu pela bela pessoa / de mim levada, e o modo ainda me ofende. // Amor, que a amado algum amar perdoa, / tornou-me, pelo seu querer, tão forte, / que como vês ainda me agrilhoa. // Amor nos conduziu a uma só morte; / Caína terá quem deliu nosso alento"./ Co' estas palavras resumiu sua sorte.

(DC, Inferno, Canto V, 100, Trad. em MAURO, 1998).

Além do amor, da política e da teologia terem norteado o desenvolvimento de sua obra, é tanto no conteúdo, quanto na forma que consistem as maiores qualidades do Dante poeta. Em termos de poesia, Dante agregava característica únicas e inéditas, como a sensação de imersão naquela realidade, nas palavras do crítico literário americano Charles S. Singleton: "É uma daquelas obras que a "ilusão de realidade é tão poderosa" que o leitor durante o ato de leitura pode-se dizer totalmente encantado por aquela ficção" (SINGLETON apud STERZI, 2010, p. 106).

Outra característica reformadora de sua obra está na linguagem escrita. No sonho atribuído à mãe de Dante por Bocaccio, o pavão tem os pés sujos, sua interpretação conta que assim o é por escrever na linguagem das ruas, e não no $\operatorname{latim}^{15}$.

Outra característica do poeta Dante Alighieri foi a pluridade de projetos simultâneos, era capaz de compor projetos literários em uma grande soma de tempo e livros diversos, no total, são obras suas além dos livros da "Comédia", "O Convívio", "O Tratado de Monarquia", a "Vita Nuova" e "De vulgari eloquentia". Obras que envolviam todo o vasto conhecimento de Dante, e algumas infelizmente inacabadas.

\subsubsection{O Peregrino: o Infinito vem ao Finito}

Quando Dante iniciou sua epopeia, conforme afirma seu próprio texto, ele deveria ter a idade de 35 anos, o que configura a metade do percurso da vida em sua

\footnotetext{
14 "Cada alma presa de gentil ardor, / Que me acolhe, no meu dizer presente, / Em que ressoe o que me vem fremente. / Saúde o seu senhor, isto é, Amor. / Eram quase três horas de fulgor / Da estrela sobre todas reluzente, / Apareceu Amor, subitamente, / E relembrar-lhe a essência dá-me horro. / Amor me parecia alegre, tendo / Meu coração na mão; e envolvia, / Nos braços minha amada adormecendo. / Logo acordou: do coração ardendo,/ Medrosa, humildemente, ela pascia, / Tão depressa o via girar, sofrendo. (Trad. em CORRÊA, 2005, p. 21).

${ }^{15}$ A importância da obra de Dante foi tamanha para a cultura italiana, que dentre as várias línguas e dialetos presentes na Penísula Itálica, o toscano, a chamada linguagem das ruas, tornou-se idioma oficial da Itália quando esta se constituiu em um Estado único (STERZI, 2010, p. 29).
} 
época ${ }^{16}$. Vale lembrar que tal idade se aproxima dos 33 anos que também foi a idade atribuída à crucificação de Cristo. ${ }^{17}$ Essa relação foi de grande impacto na vida do poeta, pois de acordo com a cronologia dos fatos de sua biografia, supunha-se que seu exílio tenha começado mais ou menos na mesma época em que começou sua obra e que ela foi para ele, uma forma de peregrinação, tal qual Cristo começou a sua aos 30 anos e finalizou com a Crucificação e a Transfiguração para o Paraíso.

A peregrinação, tal qual afirma o estudioso da Arte Sacra Cláudio Pastro (2010), é para o homem, em diversas religiões, uma forma de autoconhecimento, de re-conhecimento de si, tal qual afirma no trecho a seguir:

Entregue a si mesmo, o homem é incapaz de se reconhecer; perde-se como numa floresta obscura. Para se reencontrar, necessita tomar as próprias linhas curvas da realidade que serão agora no piso ou na parede, a Linha Contínua, o fio de existência, uma realidade transfigurada que direciona. Em linguagem cristã, o fio que permite ao homem se reencontrar é a Graça Divina, mas a Graça passa pela matéria. (PASTRO, 2010, p. 15)

Observe que a metáfora da Floresta Obscura, usada pelo autor, é a mesma usada por Dante no início da narrativa para explicar a sua situação de incapacidade de se posicionar ante ao Cosmos que estava a ponto de se fechar para sua figura.

Em sentido figurado, a arquitetura das igrejas cristãs procura estabelecer esse mesmo processo de transfiguração que alcançou Cristo e que o próprio Dante parece ter encontrado nos versos finais do seu Paraíso. Para os cristãos antigos, esse percurso encontrava uma forma na figura do labirinto e o mesmo pode ser visto em igrejas cristãs, como posiciona Lúcia Leão em sua obra A Estética do Labirinto (2002), ao colocar o desenho do labirinto da Catedral de Chartres como exemplo:

Na tradição cabalística e na alquimia, os labirintos das catedrais, também denominados de labirintos de Salomão, representam os percursos tortuosos pelo qual o fiel deve passar para alcançar o centro, o sagrado.

A Catedral de Chartres foi construída em 1235 . Em sua nave encontra-se o Caminho de Jerusalém, um diagrama labiríntico unicursal cujo padrão difere tanto do cretense quando do romano. Esse labirinto tinha uma função claramente religiosa e muitos fiéis percorriam suas circunvoluções de joelhos, em penitência. (LEÃO, 2002, p. 52).

Esses labirintos, conforme traz o próprio Pastro (2010), eram encontrados nas catacumbas dos primeiros cristãos e assim como o de Chartres, também eram chamados de Caminho de Jerusalém.

\footnotetext{
${ }^{16}$ Conforme atesta no trecho inicial deste capítulo, para Aristóteles, a idade perfeita do homem era 70 anos, logo, 35 anos seriam a metade do caminho, conforme o próprio Dante cita no primeiro verso da Comédia.

17 Tais informações foram extraídas dos podcasts realizados pelo Centro de Estudos de Dante, da Univerisidade de Leeds, no Reino Unido. Disponível em < http://www.leeds.ac.uk/italian/centrefordantestudies.htm >.
} 
A Jerusalém a que se referem é a Nova Jerusalém, cidade encontrada no Paraíso, que nada mais é que o "Deus contido no eu interior dos fiéis", como coloca a seguir:

A peregrinação, como uma marcha organizada para um centro consagrado, é a vitória sobre o espaço e o tempo. O objetivo pessoal se identifica ritualmente com o Objetivo Supremo, com o Centro Supremo, que não é senão Deus; em última análise, com a Jerusalém Celeste, o centro do Paraíso Perdido. (PASTRO, 2010, p. 18)

No período medieval, a relação do espaço sagrado com o espaço profano era muito mais clara que a existente hoje. Foucault (2006), no entanto, revela que apesar das transformações do espaço que serão descritas no tópico a seguir, o espaço hoje talvez não esteja de todo dessacralizado:

[...] apesar de todas as técnicas nele investidas, apesar de toda a rede de saber que permite determiná-lo ou formalizá-lo, o espaço contemporâneo talvez não esteja ainda interiamente dessacralizado. E talvez nossa vida ainda seja comandada por um certo número de oposições nas quais não se pode tocar: oposições que admitimos como inteiramente dadas: por exemplo, entre o espaço privado e o público, entre o espaço da família e o espaço social...; todos são ainda movidos por uma espécie de sacralização. (FOUCAULT, 2006, p. 417)

Tal percepção é claramente observada nas manifestações religiosas de peregrinação existentes ao redor do globo como o Caminho de São Tiago entre a Bélgica e a Espanha, a peregrinação a Meca dos muçulmanos e um exemplo mais próximo, o Círio de Nazaré.

Tais exemplos são mostra daquilo que será observado no próximo tópico, que apesar das revoluções técnico-científicas que o homem viveu no período entre o fim da Idade Média e o atual, a convivência com o espaço imaterial, sacralizado e com seres de outra natureza são frequentes nas culturas tanto do oriente quanto da ocidental.

\subsection{DIVINO INFERNO DE DANTE}

O livro possui o nome de Comédia, pois de acordo com o próprio Dante, se em uma tragédia grega os personagens começam em um estado de graça e terminam em desgraça, na Comédia a narrativa segue justamente o caminho inverso. Outro ponto importante para chamar seu trabalho desta forma, deve-se ao que o pesquisador Eduardo Sterzi (2010), especialista em Dante, traz no seguinte apontamento: "... porque a obra mistura estilo elevado com estilo baixo, e, portanto, se a virgiliana Eneida, que fica só no estilo elevado é Tragédia, a obra dantesca, que toma aquela como modelo, só pode ser chamada de comédia." (STERZI, 2010 p. 105). 
Há ainda o fato do livro ter ficado popularmente conhecido como "Divina Comédia", o que ocorre no entanto, é que este nome não foi empregado por Dante e sim por seu principal entusiasta, Giovanni Bocaccio (1313-1375) que acrescentou o termo "Divina" como uma espécie de reverência. Como será visto mais adiante, o também florentino Bocaccio tornou-se a principal referência e o maior estudioso da obra de Dante no período contemporâneo ao poeta, e a razão pela qual ele a batizou de Divina, deve-se ao enorme valor literário que esta obra deixou para a cultura italiana e ocidental ${ }^{18}$.

A Divina Comédia foi escrita entre 1307 e 1313 e trata-se de um relato de viagem por três reinos do outro mundo: Inferno, Purgatório e Paraíso. A viagem é contada em 100 Cantos; 33 cantos para cada um dos livros e o primeiro Canto servindo como introdução à viagem que está por seguir.

A obra levanta valores morais da cristandade que Dante acreditava estarem perdidos em sua época. A literatura da obra, busca trazer a salvação espiritual a partir das quatro virtudes cardeais, entendidas por Dante em seu mundo medieval: Força, Justiça, Prudência e Temperança e as três virtudes teológicas: Justiça, Fé e Caridade.

A Comédia, como originalmente era chamada por seu autor, traz à realidade um mundo ideologicamente virtual, possível somente nas crenças cristãs medievais. Discute política e espiritualidade sem distinção entre o racional e o religioso e possui alguns aspectos importantes marcados na compreensão do mundo medieval e da cultura do Ocidente até os dias atuais.

Os estudiosos de sua obra da literatura ocidental a posicionam como uma das obras mais importantes da história, respeitando seu caráter de clássico da literatura universal, primeiramente, por criar um novo estilo, em que Dante mistura constantemente o clássico com o vernacular, onde em uma mesma frase é capaz de permutar relações entre seres mitológicos da Antiguidade e contemporâneos a sua época. Essa força encontrada no texto dantesco é marcada pela ruptura das formas tradicionais da literatura de então, pelo caráter clássico que a obra tem e pelo caráter extramente "moderno", em que autores e críticos literários o colocam, ao lado de Shakespeare como um dos grandes escritores de seu tempo, conforme descreve Sterzi, nas palavras de T. S. Eliot: "Dante e Shakespeare dividem o mundo moderno entre si; não há terceiro" (STERZI, 2010, p. 16)

A começar a descrição literal do Inferno de Dante, salienta-se características que são importantes para seu entendimento. Dante, ousa-se dizer, foi um poeta que teve seus altos e baixos em relação ao reconhecimento de sua importância literária,

${ }^{18}$ STERZI (2010, p. 17). 
conforme afirma Sterzi: "Projetadas num gráfico, as significativas oscilações da fama de Dante nos séculos seguintes desenhariam, para um observador atento, os movimentos não lineares - contraditórios e dialéticos - pelos quais constituiu a moderna cultura literária italiana e europeia." (STERZI, 2010, p. 15)

Sterzi expõe, a partir desta conjuntura, que a leitura de Dante era revolucionária demais para sua época e para as épocas seguintes: "Dante era misturado demais - vulgar demais, complexo demais - para o gosto médio "humanista" e, depois, "iluminista"." (STERZI, 2010, p.15). Disto isto, observa-se que sua leitura tomou fôlego, principalmente, com o fenômeno romântico do século XIX, em que a conjuntura social que levou à modernidade de Baudelaire se adaptava ao aparente caos presente no poeta florentino, conforme lembra no trecho abaixo:

Dante - em alguns aspectos medularmente medieval, em outros anunciador dos novos tempos que seriam conhecidos pelo rótulo impreciso de "Renascimento" - só alcançou uma mais ampla legibilidade nos séculos XIX e XX: sem medo de anacronismo, pode-se dizer que sua obra é, em alguma medida, um fenômeno romântico e moderno. Francesco D'Ovídio tem razão quando em 1901, lembrando a então recente proliferação dos estudos dantescos, diz que o "século XIX" se pode, por outros motivos, ser definido como o século do vapor ou da eletricidade ou das ordens livres ou das reivindicações nacionais, nós poderíamos com idêntica razão saudá-lo como o século de Dante. (STERZI, 2010, p. 16)

Os motivos que levaram à classificação de o Século de Dante, por Sterzi, estão relacionados com a crescente procura por sua obra em estudos acadêmicos e artísticos, que não findaram e ainda hoje estão presentes na procura pelo conhecimento da natureza humana. Nesta linha de pensamento, o poeta Jorge Luiz Borges refere-se a este trabalho da seguinte forma:

Há uma primeira leitura da Comédia; não há uma última, já que o poema, uma vez descoberto, segue acompanhando-nos até o fim. Como a linguagem de Shakespeare, como a álgebra ou como nosso próprio passado, a Divina Comédia é uma cidade que nunca teremos explorado de todo; o mais gasto dos tecetos pode, uma tarde, revelar-me quem sou ou o que é o universo. (BORGES citado por STERZI, 2010, p. 104)

A imagem que persiste hoje do Inferno na visão de Dante, explica-se diante da materialidade que o Inferno permite, pois quanto mais Dante vai se aproximando do Paraíso, suas referências imagéticas vão tornando-se também mais imateriais, chegando ao ponto de uma incompreensão em determinados versos. No prefácio de Ivan Junqueira para o livro Viagem com Dante, de Oscar Dias Corrêa (2005), ele apresenta a Comédia como "a identidade do Inferno com a vida turbulenta, odiosa e vingativa do Trecento em Florença, a identidade da vida de Dante com o Purgatório e a realidade do Paraíso." (CORRÊA, 2005, p. 14). 
De certa forma, o que ele chama de "a vida odiosa, turbulenta e vingativa" do Trecento em florentino repete-se em diversos momentos da história até os dias atuais, o que garante audiência aos estudos da Comédia, sobretudo, do Inferno. Como este trabalho foca nas imagens do Inferno, convém um diagrama da estrutura proposta por Dante ao submundo. Vale lembrar, que esta estrutura é proveniente de referências que teve em sua época. Como expõe Umberto Eco (2007), em seu livro História da Feiura, a inspiração para o Inferno de Dante veio fundamentalmente de algumas obras já difundidas em seu tempo como, por exemplo, a Navegação de São Brandão, a Visão de Tundalo, Babilônia Infernal, de Giacomino da Verona, o Livro das Três Escrituras, de Bovensin de la Riva e, principalmente, na Eneida, do poeta Virgílio e do Livro da Escada que narra a viagem de Maomé ao além-túmulo. Para a melhor compreensão desta visão do inferno, alguns exemplos:

\subsubsection{O Inferno de São Brandão}

Essa é a descrição inicial do Inferno na visão de São Brandão, primeiramente descrevendo um lugar totalmente inóspito, que irá ainda ter um ar industrial quando inserir em sua visão as ferrarias que farão parte do cenário, juntamente com o fedor e a feiura de seus habitantes.

Tendo ido com o vento para os lados de Aquilone, eles viram uma ilha cheia de pedras grandes que era muito suja, e não havia árvores, nem folhas nem relvas nem flores nem frutos. E cada forja tinha o seu ferreiro, e todas tinham seu ferro que ao ferreiro pertenciam e suas forjas ardiam como ardentíssimos fornos, e cada um martelava com tanta força e com tanto rumor, que se fosse outra coisa que não o Inferno aqui pareceria demasiado. (SÃO BRANDÃO citado por ECO, p.85, 2007)

Um ponto interessante desta narrativa é que os que navegavam com São Brandão estenderam a vela e oraram a Deus para escaparem daquela ilha, o que se mostrou eficiente ao final. A narrativa de São Brandão data do século $X$ e é uma das primeiras ilustrações medievais do Inferno, que o posiciona como um lugar específico da Terra, que é possível chegar através de navegação. Arqueólogos identificaram uma missão datada no século $X$, presente na América do Norte, cerca de 500 anos antes de Colombo ou das Grandes Navegações, sabe-se claramente que era uma missão religiosa e acredita-se que se deve à chegada de São Brandão ${ }^{19}$. Logo, esta descrição

\footnotetext{
${ }^{19}$ Extraído do documentário “Os primeiros descobridores da América” exibido pelo History Channel em 2010.
} 
do Inferno, segundo ele, pode estar associada a algum povo ameríndio que encontraram no meio da rota.

1.3.2 O Inferno de Maomé.

E depois vi uma grande multidão de mulheres, em número quase incrível, e todas presas pela matriz a grandes candentes. E elas pendiam de correntes em fogo, tão extraordinariamente ardentes que ninguém poderia expressá-los. E perguntei a Gabriel quem eram aquelas mulheres, e ele respondeu que eram meretrizes que nunca abandoram a fornicação e a Luxúria. (MAOMÉ citado por ECO, p.87, 2007)

No Inferno de Maomé, ao contrário na epopeia de Dante, onde se refere à Luxúria se encontram não os amantes, mas as meretrizes. Justamente neste ponto é que algumas diferenças entre o Cristianismo e o Islã vêm à tona, pois para o cristianismo a relação de pecado não está no ato em si, mas no desejo, talvez por isso não existam a presença de prostitutas na narrativa dantesca.

Os castigos no "Livro da Escada", de Maomé são muito mais físicos que os castigos encontrados no Inferno de Dante que, em alguns momentos, chega a ser até mesmo poético como no caso da luxúria, em que os amantes são expostos a um turbilhão, a um estado quase gasoso de matéria.

\subsubsection{A Eneida de Virgílio}

A maior referência para a constituição do Inferno de Dante foi sem dúvida a Eneida, do poeta Virgílio, que é visto como guia durante sua jornada pelo Inferno e parte do Purgatório. Não é à toa sua escolha, teóricos da cultura ocidental observam que a Grécia chegou até os dias atuais através de Roma e o responsável por esta transição foi o poeta da Eneida, conforme observa Ivan Junqueira (CORRÊA, 2005). Sterzi (2010) cita sua obra da seguinte forma:

[...] o básico da topografia - que se tornaria dantesca - do outro mundo já está aqui: Enéias desce por um vestíbulo; encontra lá embaixo o campo dos mortos sem sepultura, o rio Estige (Styx), o campo das aflições e as últimas campinas antes das bifurcação que, pelo caminho da esquerda leva ao Tártaro (mal traduzindo, Inferno) e, pelo da direita, depois de se transpor as muralhas de Dis (Plutão, rei dos Infernos origem do nome da cidade de Dite, com que Dante depara no Inferno), conduz aos Campos Elíseos (lugar paradisíaco, atrás do qual há o bosque sagrado e enfim, o rio do esquecimento, Letes)." (STERZI, 2010, p. 117)

Desta, vale entender o inferno a partir da estrutura proposta por Dante para ele, onde posiciona nove círculos, de onde distribui o limbo e os quatro vícios capitais 
para o homem medieval: Incontinência, Violência e Bestialidade; Fraude Simples e, por fim, o que para ele era o pior dos pecados: a Traição.

\subsection{A COSMOGONIA MEDIEVAL: DEMÔNIOS, ANJOS, SERES IMATERIAIS E O INFERNO.}

De acordo com Werthein (2001), na tradição medieval, uma pessoa comum tinha uma relação com seres imateriais e entidades celestiais ou supra celestiais como algo muito mais concreto do que pode ser concebido nos dias de hoje. O livro "Uma História do Espaço: de Dante à Internet", escrito pela autora, mostra que a convivência com os seres imateriais fazia parte de uma cadeia natural:

Na visão medieval do mundo, o universo em sua totalidade e tudo o que nele havia estavam interligados numa grande hierarquia metafísica, por vezes chamada de a Grande Cadeia do Ser, que descendia de Deus. No topo dessa cadeia, na posição mais próxima de Deus, estavam as ordens dos seres angélicos - os querubins, serafins, arcanjos e assim por diante. Depois desses seres celestes vinham os seres humanos. Depois de nós vinham os animais, as plantas e por fim os seres inanimados. (WERTHEIN, 2001, p.24)

$\mathrm{Na}$ cadeia de seres expostas acima, o homem se inseria como centro do Universo não necessariamente pela posição celeste da Terra, mas por ser o elemento central e que, ao mesmo tempo, em que possuía uma alma intelectiva e imaterial, também era dotado de corpo e matéria.

Para o filósofo Michel Foucault: "... o espaço que hoje aparece no horizonte de nossas preocupações, de nossa teoria, de nossos sistemas não é uma inovação: o próprio espaço na experiência ocidental tem uma história" (FOUCAULT, 2006, p.411), o que nos remete às referências espaciais estabelecidas na Idade Média e que ainda estão presentes na atualidade. Como já foi dito, a convivência com seres imateriais e materiais fazia parte da realidade do homem deste tempo, até por isso, a forma de se compreender o mundo deveria obrigatoriamente abarcar este mundo metafísico tal qual os Atlas e os serviços de Georeferência da atualidade.

Foucault entendia o espaço na Idade Média como "...um conjunto hierarquizado de lugares: lugares sagrados e lugares profanos, lugares protegidos e lugares, pelo contrário, abertos e sem defesa, lugares urbanos e lugares rurais" (FOUCAULT, 2006, p. 411), e ainda para o conhecimento cosmológico "havia lugares supracelestes opostos ao lugar celeste; e o lugar celeste, por sua vez, se opunha ao lugar terrestre" (FOUCAULT, 2006, p. 411).

Para o homem esclarecido na Idade Média, e supunha-se que Dante era um desses, a Terra era redonda, apesar de erroneamente termos a ideia que, para a Idade Média, a terra era chata e que Galileu sofreu ante a Inquisição por dizer o 
contrário, na verdade, já era um consenso de que a o planeta era redondo, tendo na sua parte inferior o chamado "hemisfério austral". O que realmente legou problemas ao cientista italiano de acordo com Foucault foi o fato de "ter construído um espaço infinito, e infinitamente aberto; de tal forma que o lugar da Idade Média se encontrava aí de uma certa maneira dissolvido" (FOUCAULT, 2006, p. 414). A própria referência do cosmos, tal como revela Werthein (2001), posiciona o globo como uma esfera, central às esferas celestiais (Figura. 1).

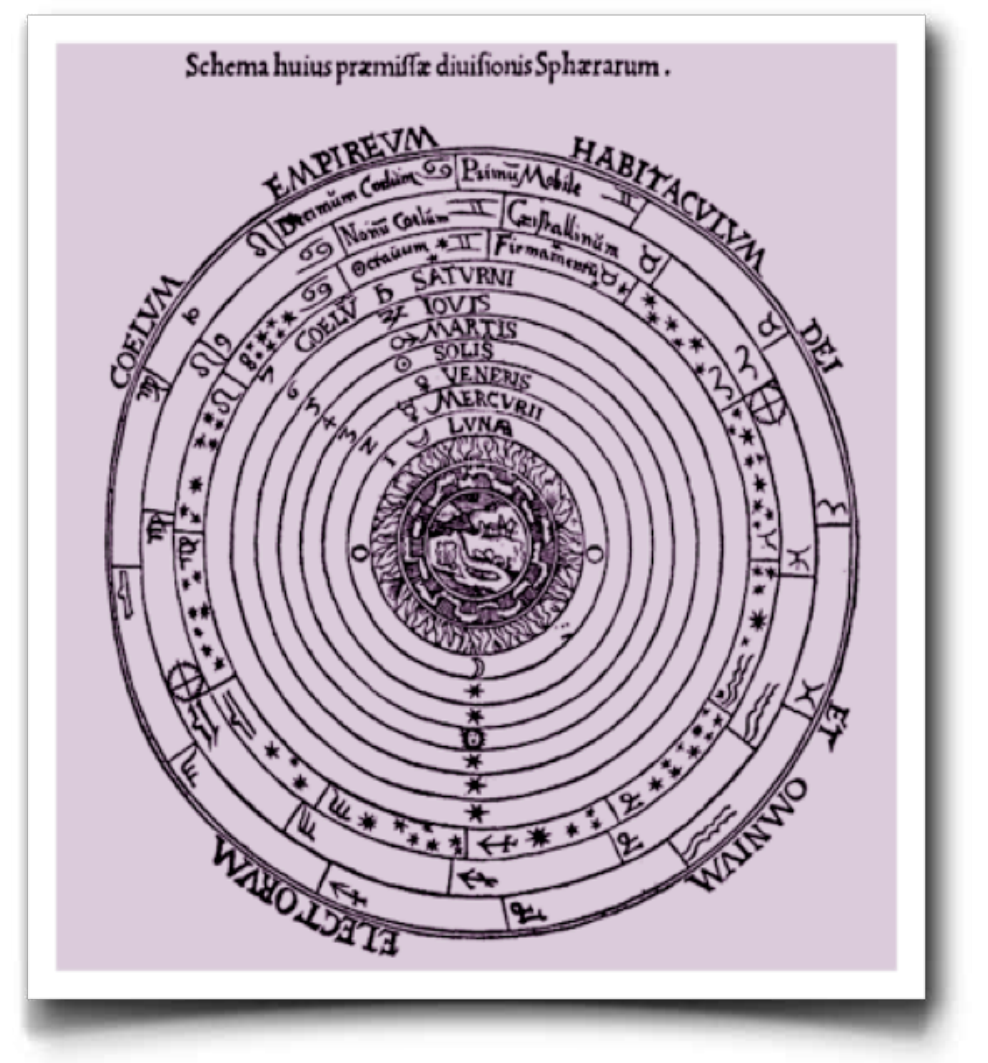

Figura 1: Mapa do cosmos medieval. Fonte: WERTHEIN (2001).

Este cosmos era composto de apenas dez esferas centradas na Terra e seguida dos planetas entre os quais o Sol fazia parte. Depois do Universo físico, existia uma fronteira: a primum mobile ${ }^{20}$ e após ela se encaminhava para o Empíreo, que era o Céu de Deus, de onde Dante escreveu o último volume ${ }^{21}$ de a Divina Comédia. Conforme este mapa, tudo o que é material se dilui ao afastar-se da Terra; da mesma forma, o Inferno encontra-se nas entranhas do planeta e sua entrada está em uma cloaca, uma abertura encontrada na Selva Escura, que Dante não situou geograficamente, conforme relata Werthein (2001):

\footnotetext{
${ }^{20}$ Dentro do modelo geocêntrico da Astronomia Medieval, o primum móbile é a esfera das constelações fixas e a última esfera antes do Empíreo.

${ }^{21}$ O Paraíso.
} 
Antes da era da cartografia fundada na matemática, os mapa-mundi europeus representavam, em geral, apenas uma única massa de terra, o hemisfério norte, com Jerusalém no meio. Nesses mapas, o Paraíso Terrestre (ou Jardim do Éden) era frequentemente desenhado como uma ilha ao largo da costa mais ao Oriente, um detalhe colhido da Bíblia. (WERTHEIN, 2001, p.41)

A falta de conhecimento do Universo e da esfera terrestre levava a suposições de como seria formado o Cosmos, sendo o medieval bem diferente do entendimento que se tem dele hoje. O desenvolvimento do conhecimento científico enfrentou as barreiras impostas pela Igreja pelo simples fato de que as propostas de Galileu, Copérnico, Descartes e os outros que vieram, não só provavam que a Terra gira em torno do Sol, mas elas simplesmente destruíam toda a concepção cosmogônica que vigorara nos primeiros mil anos da Era Cristã. Os grandes temores que geraram as perseguições inquisitórias aos homens da Ciência tinham entre seus principais medos, uma possível morte de Deus.

O cosmos de Dante é o medieval e sua jornada por ele, durou sete dias pelos três reinos do além-mundo, fazendo referência aos sete dias da criação do Universo, segundo a Teoria Criacionista ${ }^{22}$. São 33 cânticos, assim como 33 foi a idade atribuída à crucificação de Cristo e três são os reinos do outro mundo, assim como Deus é dividido em Pai, Filho e Espírito Santo para os cristãos católicos ${ }^{23}$.

Além do Inferno, os outros reinos vão se tornando cada vez mais fluidos conforme Dante aproxima-se do Empíreo, o que apresenta o Inferno como o reino mais palpável. A estrutura do Inferno é concêntrica, formada por uma sequência de vales e valas como uma grande cratera provocada pela queda de Lúcifer, o Anjo da Luz que se torna Senhor do Submundo dentro da mitologia católica, retratada na ilustração de Gustave Doré (Figura 2).

${ }^{22}$ Criacionismo é o nome empregado à teoria que acredita que a Terra e a vida humana surgiram conforme o Livro da Gênese, na Bíblia.

${ }^{23}$ STERZI (2010, p. 26). 


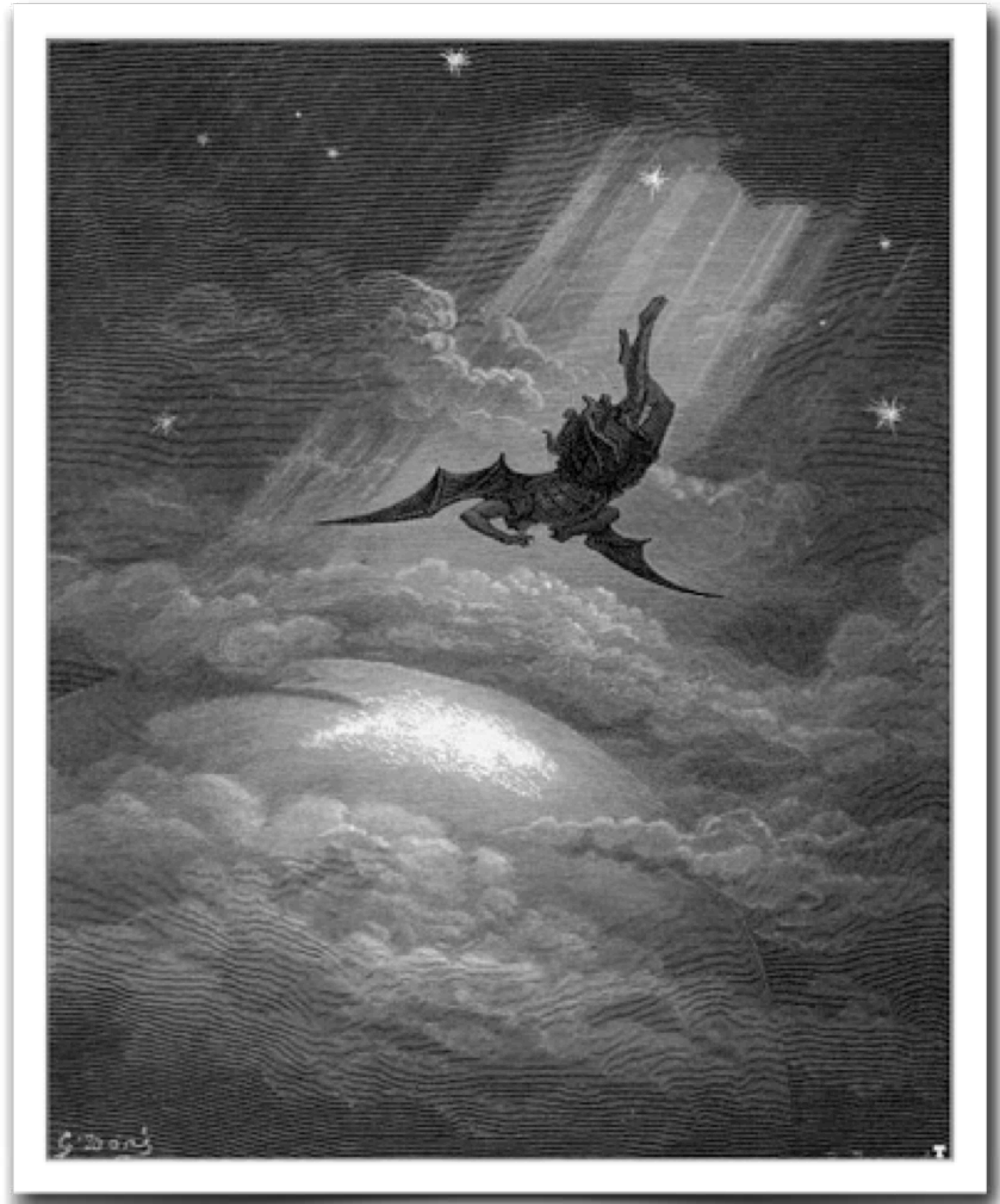

Figura 2: Paraíso Perdido, ilustração de Gustave Doré. Fonte: Capellari. 


\subsubsection{Estrutura do Inferno de Dante}

Ao todo são nove Círculos Infernais, onde as almas são distribuídas de acordo com a gravidade de seus vícios (Tabela 1 ).

\begin{tabular}{|c|c|c|c|c|c|}
\hline \multirow[t]{2}{*}{ PECADO } & \multicolumn{2}{|r|}{ CÍRCULO } & \multicolumn{2}{|c|}{ PECADORES } & CANTO \\
\hline & \multicolumn{2}{|l|}{ Vestíbulo } & \multicolumn{2}{|l|}{ Ignavos } & III \\
\hline & \multicolumn{2}{|l|}{ I } & \multicolumn{2}{|c|}{ Sem batismo } & IV \\
\hline \multirow{5}{*}{ Incontinência } & \multicolumn{2}{|l|}{ II } & \multicolumn{2}{|c|}{ Luxuriosos } & $\mathrm{V}$ \\
\hline & \multicolumn{2}{|l|}{ III } & \multicolumn{2}{|c|}{ Gulosos } & VI \\
\hline & \multicolumn{2}{|l|}{ IV } & \multicolumn{2}{|c|}{ Avaros e Pródigos } & VII \\
\hline & \multicolumn{2}{|l|}{ v } & \multicolumn{2}{|c|}{ Iracundos e Rancorosos } & VII-VIII \\
\hline & \multicolumn{2}{|l|}{ VI } & \multicolumn{2}{|c|}{ Heréticos } & IX-X \\
\hline \multirow{4}{*}{$\begin{array}{l}\text { Violência e } \\
\text { Bestialidade }\end{array}$} & VII & Giro 1 & Próximo & $\begin{array}{l}\text { Tiranos, } \\
\text { Assaltantes }\end{array}$ & XII \\
\hline & & Giro 2 Contra: & \multirow[t]{3}{*}{$\begin{array}{l}\text { Si Próprio } \\
\text { Deus }\end{array}$} & $\begin{array}{l}\text { Suicidas- } \\
\text { Gastadores } \\
\text { Blasfêmios }\end{array}$ & XIII \\
\hline & & \multirow[t]{2}{*}{ Giro 3} & & Sodomitas & $X I V-X V$ \\
\hline & & & & Usurários & XVI-XVII \\
\hline \multirow{10}{*}{$\begin{array}{l}\text { Fraude } \\
\text { Simples }\end{array}$} & \multirow{10}{*}{ VIII } & Vala 1 & \multicolumn{2}{|c|}{ Sedutores Rufiões } & XVIII \\
\hline & & Vala 2 & \multicolumn{2}{|c|}{ Aduladores-Lisonjeadores } & XVIII \\
\hline & & Vala 3 & \multicolumn{2}{|c|}{ Simoníacos } & XIX \\
\hline & & Vala 4 & \multicolumn{2}{|c|}{ Magos-Adivinhos } & $X X$ \\
\hline & & Vala 5 & \multicolumn{2}{|c|}{ Traficantes } & XXI \\
\hline & & Vala 6 & \multicolumn{2}{|l|}{ Hipócritas } & XXIII \\
\hline & & Vala 7 & \multicolumn{2}{|l|}{ Ladrões } & XXIV-XXV \\
\hline & & Vala 8 & \multicolumn{2}{|c|}{ Maus Conselheiros } & XXVI-XXVII \\
\hline & & Vala 9 & \multicolumn{2}{|c|}{ Cismáticos-Intrigantes } & XXVIII \\
\hline & & Vala 10 & Falsários & & XXIX-XXX \\
\hline & & Caína & & Parentes & XXXII \\
\hline & & Antenora & & Pátria & XXXII \\
\hline Traição & IX & Ptolomeia & Contra & Hóspedes & XXXIII \\
\hline & & Judeca & & Benfeitores & XXXIV \\
\hline
\end{tabular}

Tabela 1: Configuração do Inferno. Fonte: MAURO, 1998.

Uma das imagens contemporâneas do mapa do Inferno de Dante mais didáticas é a presente no site do webdesigner e entusiasta de Dante, Helder Rocha ${ }^{24}$ que apresenta um mapa do Inferno que se distribui conforme a descrição encontrada na Literatura (Figura 3). Além da imagem apresentada por ele, existem diversos outros artistas ao longo dos séculos que ilustraram como seria esta visão topográfica do Inferno de Dante:

${ }^{24}$ Disponível em: <www.stelle.com.br $>$. 


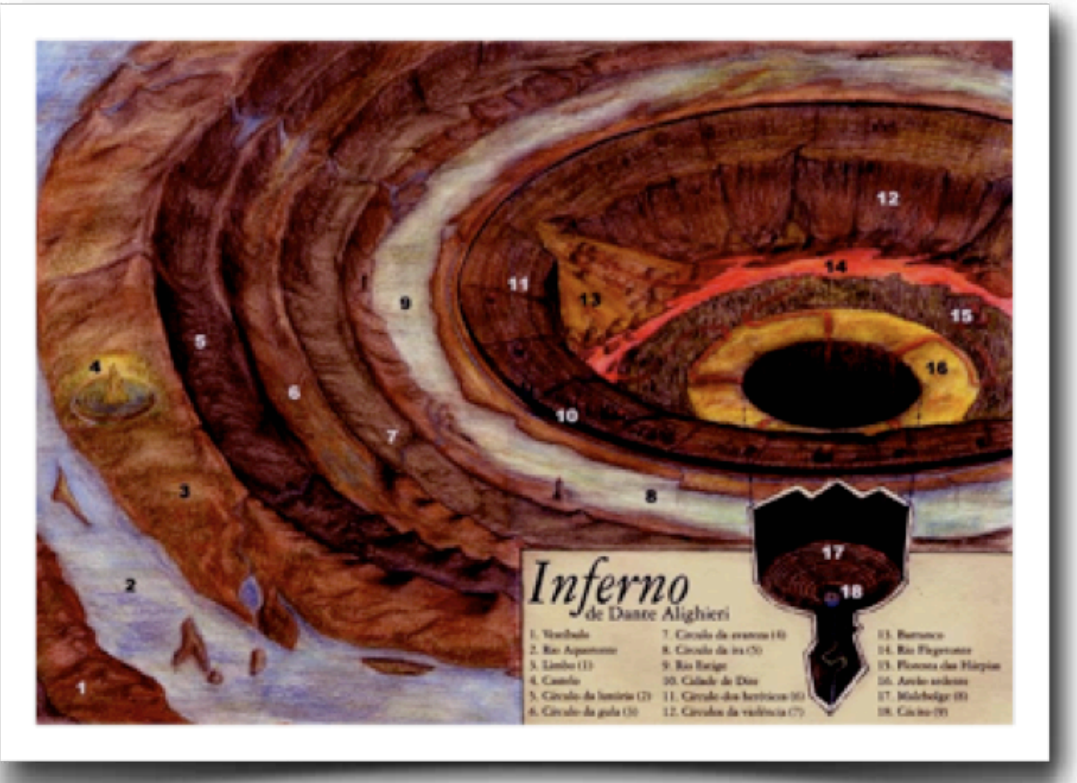

Figura 3: Mapa do Inferno, ilustrado por Helder Rocha (2001). Fonte: <www.stelle.com.br>.

Entre os artistas supracitados, destacam-se Sandro Boticcelli (Figura 4) e do ilustrador do século XV, Bartolomeo (Figura 5), conforme ilustrações abaixo.

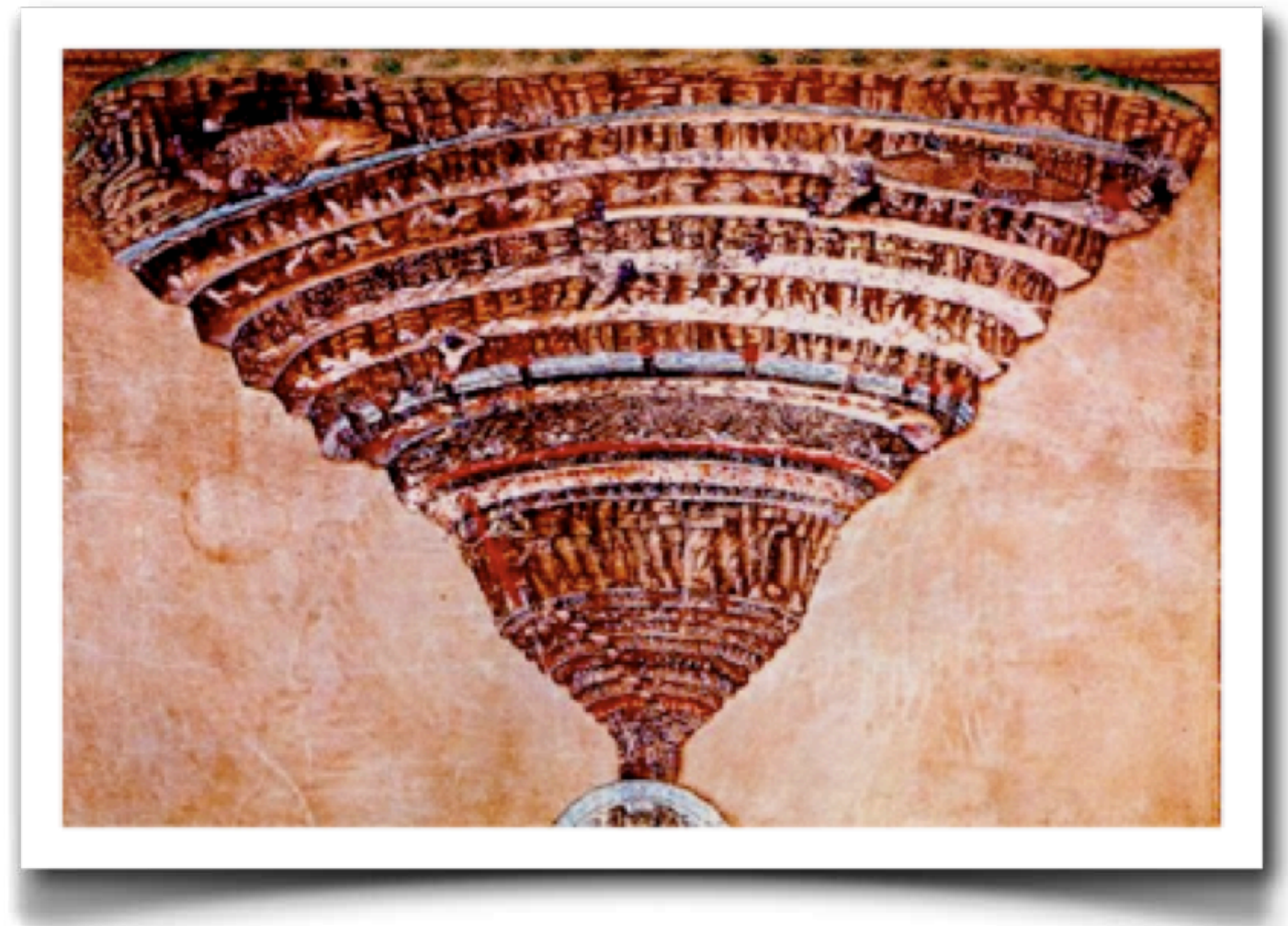

Figura 4: Mapa do Inferno, de Sandro Botticcelli Fonte: <www.stelle.com.br>.

Nesta primeira ilustração de Sandro Botticcelli, observa-se um afunilamento, tal qual é descrito por Dante como um conjunto de círculos que vão se afunilando em 
uma grande cratera onde, ao final, uma grande vale guarda o lugar mais frio do inferno, cercado por uma esfera azul.

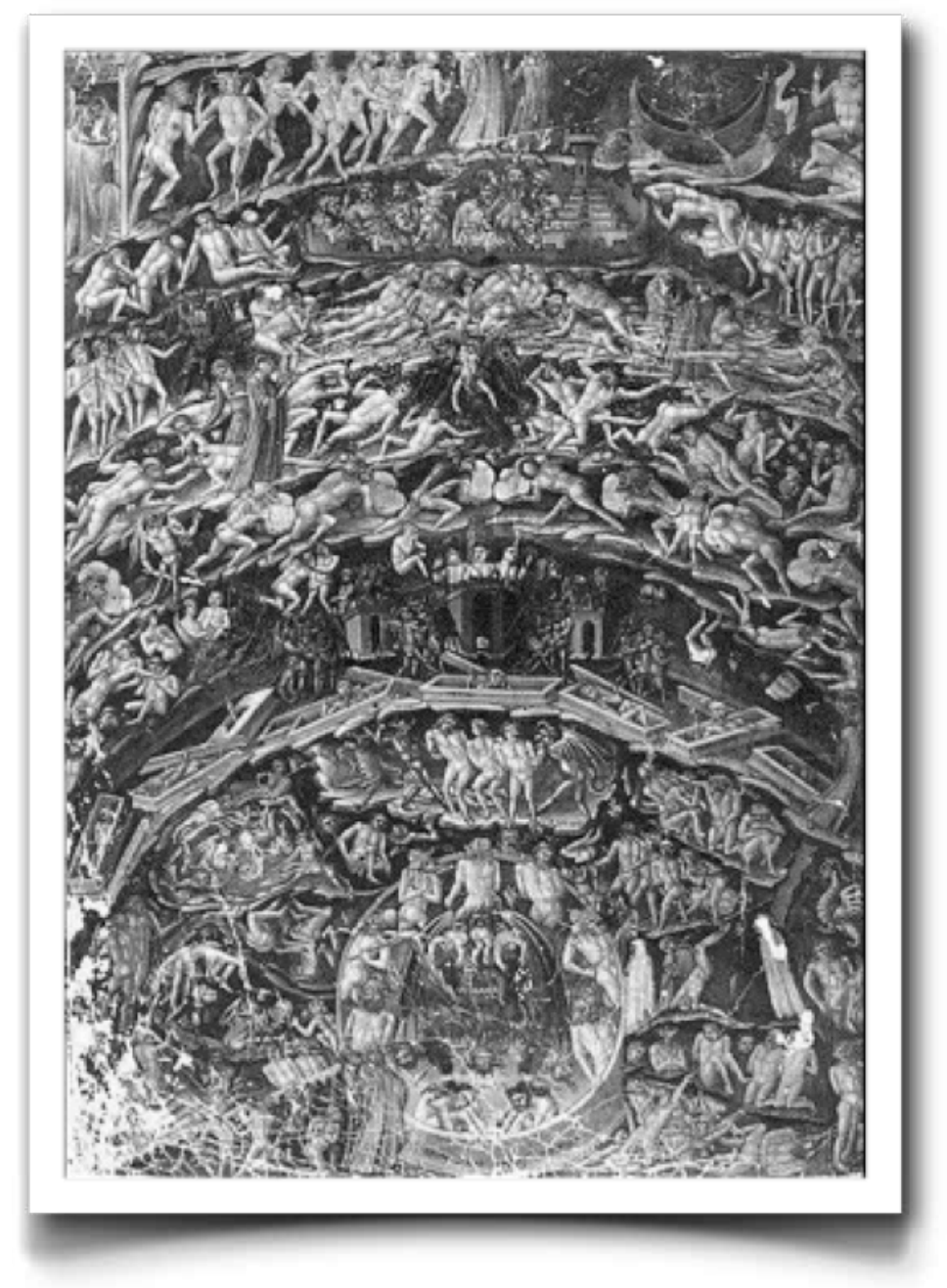

Figura 5: Mapa do Inferno, de Bartolomeu (século XV). Fonte: <www.stelle.com.br $>$.

Nesta imagem do ilustrador da Renascença, Bartolomeu, os círculos infernais se apresentam de uma forma muito mais figurada como se fossem formados simplesmente por almas em direção ao centro como em um redemoinho. Os desenhos dos demônios se misturam ao das almas e os elementos topográficos como os rios e as crateras são dados por meio de simbolismos como os barcos e castelos que servem pra posicionar os cânticos dentro da gravura. 


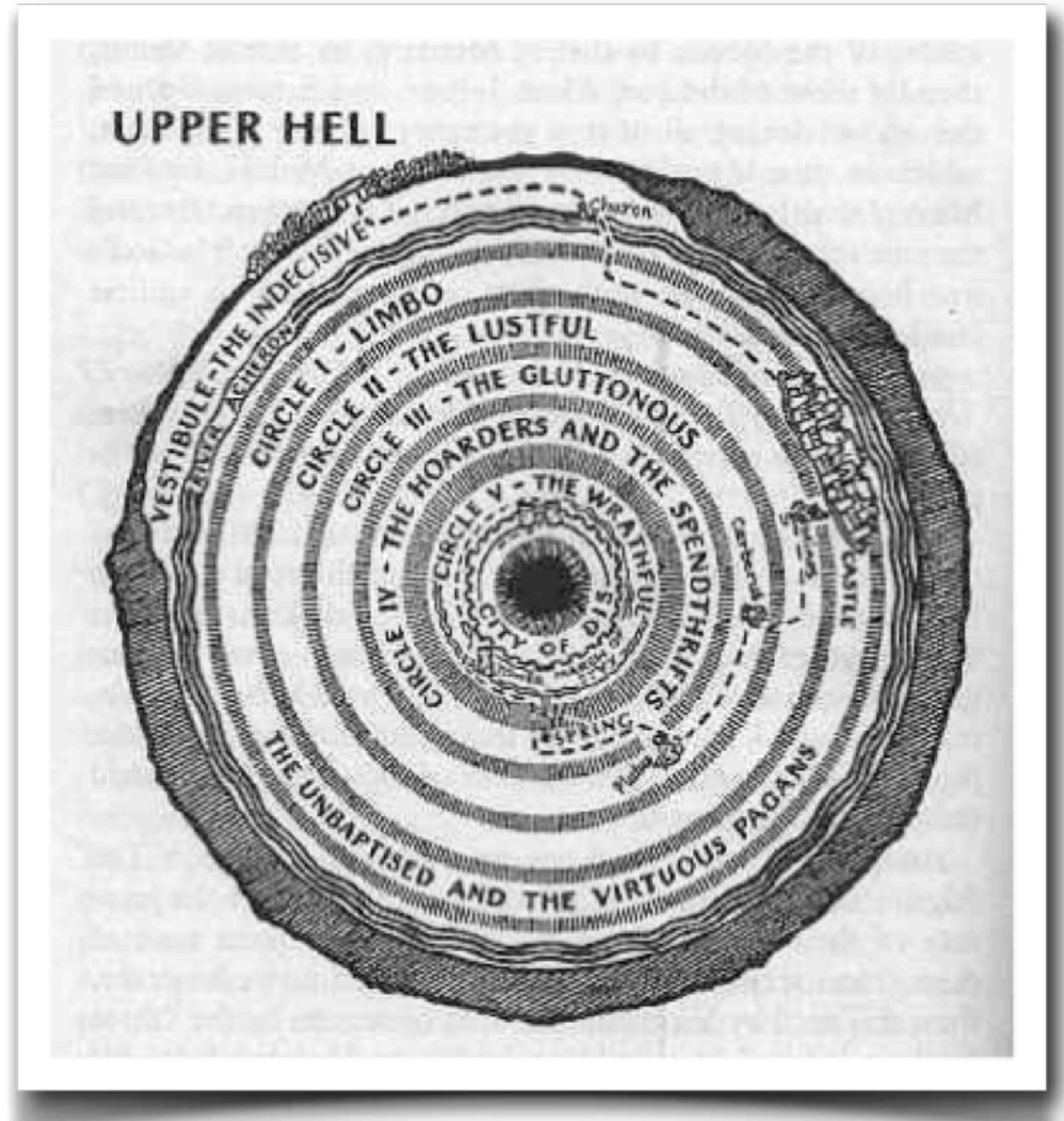

Figura 6: Mapa do Inferno, de Gustave Doré. Fonte: Capellari.

Todas as representações do mapa do Inferno retratam a forma de uma cratera, onde quanto mais profundo, maiores os castigos e maior a gravidade das faltas que cometeram as "almas" ali encerradas. Mais adiante, será feita uma jornada pelo mesmo percurso que Dante seguiu juntamente com Virgílio, desde a "Floresta Escura", com seus significados, até o último círculo infernal, mas antes de iniciar por esta seara, é necessária a compreensão de alguns conceitos relativos ao universo medieval que estão encerrados na estrutura cosmogônica do Inferno e que divergem em muitos aspectos, dos significados dados a estes conceitos nos dias de hoje, dentre os quais destacam-se o amor e a gula, relacionados diretamente à Incontinência e outros conceitos importantes como o livre arbítrio e a moral cristã.

\section{Conclusão}

A Figura de Dante Alighieri revela-se importante não somente para sua cidade, mas como foi visto, para a própria Itália e a sociedade ocidental. A partir de elementos próprios, extraídos de sua cultura, dos embates políticos, da sua formação 
intelectual, ele construiu uma obra literária capaz de sintetizar uma época: A Idade Média, e o resultado de seu trabalho permitiu uma revolução intelectual que seguiu-se ao Renascimento. O exercício de re-construção deste personagem através dos tempos mostra que a sociedade contemporânea, mesmo com as revoluções provocadas pelas neo-tecnologias comunicacionais, possui relações interpessoais que ainda necessitam de estudos mais aprofundados. Na época de Dante, o Universo era outro, as cidades eram menores, mas a forma de relacionar-se com a cidade já se situava em um cenário político, econômico e cultural.

É lógico que essas variáveis ganharam outros elementos: há o marketing, a produção imagética contemporânea e a veiculação dessas imagens através do cinema, dos quadrinhos, da televisão e das mídias digitais. O próprio Dante, ainda hoje é retratado desta forma, em versões Anime para o Inferno de Dante ou na série Spawn para os quadrinhos. Filmes como "Amor além da Vida" ou mesmo seu perfil publicado em redes de relacionamento corroboram com a re-construção de seu personagem no mundo contemporâneo. As imagens reveladas por ele foram reconstituídas através dos séculos por escritores e artistas visuais, de Bocaccio a Rodin, passando por Delacroix, Boticcelli, entre outros. Isto mostra a situação deste eurudito qua ainda hoje, sete séculos depois, possui uma relação com sua cidade que vai além de Florença, mas com o Inferno que existe dentro de cada ser contemporâneo, observado nas mídias e no comportamento.

\section{Referências}

ALIGUIERI, Dante. A Divina Coméda: Inferno. Trad. Ítalo Eugênio Mauro - Ed. 34. Texto: Prefácio. Ítalo Eugênio Mauro. São Paulo SP 1998

BENÉVOLO, Leonardo. A História da Cidade. Ed. Perspectiva. São Paulo SP 1997.

BECKER, Udo. Dicionário de Símbolos. Ed. Paulus. São Paulo SP 1999.

COSTA, Mário. O Sublime Tecnológico. Trad. Dion Davi Macedo. Ed. Experimento. São Paulo-SP 1995.

CORRÊA, Oscar Dias. Viagem com Dante. Top Books Editora, Rio de Janeiro RJ. 2005.

ECO, Umberto. História da Feiúra. Ed. Record. Rio de Janeiro RJ 2007.

FRANCO Jr., Hilário. Dante, O Poeta do Absoluto. Ateliê Editorial. Cotia SP, 2000.

FOUCAULT, Michel. 1984, Outros Espaços. In Ditos e Escritos. Manuel Barros da Mota (Org). (Inês Autran Barbosa trad.) Ed. Forense Universitária, Rio de Janeiro- RJ. 2006.

JUNQUEIRA, Ivan. Prefácio In O. D. Corrêa. Viagem com Dante. Top Books Editora, Rio de Janeiro RJ. 2005.

LEÃO, Lúcia. A Estética do Labirinto. Ed. Anhembi Morumbi. São Paulo SP, 2002. 
PASTRO, Cláudio. A Arte no Cristianismo: Fundamentos, Linguagem, Espaço. Ed. Paulus. São Paulo S,P 2010.

STERZI, Eduardo. Por que ler Dante. Ed. Globo. São Paulo SP, 2010.

WERTHEIM, Margaret. Uma História do Espaço, de Dante à Internet. Trad. Maria Luíza X. de A. Borges. Jorge Zahar Editora, Rio de Janeiro - RJ 2001. 